\title{
Hablamos de niñas
}

Violencia estatal contra mujeres

Analía E. Aucía

Abogada y Mg. en Derecho (UNR)

E-mail: analia_aucia@hotmail.com 
Resumen

El interés de este trabajo es mostrar la tensión existente entre ciertas prácticas estatales que ejercen violencia contra las mujeres y las normativas que protegen a las mujeres de todas las formas de violencia y discriminación que deben ser aplicadas por esas mismas instancias estatales. Para tal fin, se analizan cuatro situaciones en las que diversos agentes estatales ejercieron violencia institucional hacia niñas de entre 9 y 12 años. La elección de trabajar con situaciones que afectaron a niñas responde, fundamentalmente, a que el Estado debe tomar medidas de especial protección por la condición de infantes. El análisis de tal accionar busca visibilizar lo que la propia actuación estatal invisibiliza mostrando la responsabilidad del Estado en la producción de violencia cuando su obligación es eliminarla. Para esto se hará referencia a las normativas vigentes que delimitan el marco de legalidad y la ética de nuestras prácticas, haciendo hincapié en la relevancia de los instrumentos de derechos humanos. Para comprender la naturalización de ciertas formas de violencia instalada en las prácticas y discursos institucionales, se analizarán brevemente algunas maneras en las que el conocimiento filosófico ha sostenido la construcción de las identidades de género y la desigualdad que le es propia.

\section{Palabras claves}

violencia institucional - violencia de género - violencia infantil

\section{Abstract}

The interest of this work is to show the tension between certain state practices that resort to violence against women and regulations that protect women from all forms of violence and discrimination that must be implemented by these state agencies. To that end, four situations in which state agents exerted different institutional violence towards girls between 9 and 12 years are analyzed in this work. Choosing to work with cases that affected girls responds mainly to the State taking special protection measures because of their infant condition. The analysis of such action intends to make visible the invisible government action itself, showing the state's responsibility in the production of violence when its obligation is to eliminate it. Therefore, current regulations that define the framework of legality and ethics of our practices will be referred to in this paper, emphasizing the relevance of human rights instruments. To understand the naturalization of certain forms of violence mounted in institutional practices and discourses, some ways in which philosophical knowledge has supported the construction of gender identities and its own inequality will be briefly discussed.

\section{Key words}

institutional violence - gender violence - violence against children 


\section{Introducción}

El propósito de este trabajo es aportar elementos para la visibilización de la violencia institucional contra las mujeres basadas en su sexo, particularmente la violencia ejercida contra niñas, según la conceptualización que asume la ley de Protección Integral para Prevenir, Sancionar y Erradicar la Violencia contra las Mujeres en los ámbitos en que desarrollen sus relaciones interpersonales $\mathrm{N}^{\circ} 26.485$ (de aquí en adelante Ley de Protección Integral).

El foco de análisis está puesto en las intersecciones producidas entre, por un lado, ciertos fundamentos teóricos que subyacen en la producción estructural de la violencia contra las mujeres, la cual se presenta naturalizada ${ }^{1}$ para un amplio sector de la sociedad y, por otro, las normativas nacionales e internacionales que obligan al Estado a eliminar la violencia contra las mujeres, incluso la ejercida desde el propio accionar estatal y, por último, las prácticas y decisiones de los agentes estatales cuando deben resolver o intervenir en situaciones de violencia que involucran a niñas.

El objetivo, por una parte, es mostrar que la prolífica existencia de normativas que protegen a las mujeres contra la violencia basada en su género, y en particular a las niñas con medidas de especial protección, no sólo no hace disminuir la violencia sino que la misma persiste a través de diversas prácticas y discursos de agentes estatales, algunos de los cuales - paradójicamente- se afirman en un lugar político de "protectores" de derechos o de reparación de los daños causados, por ejemplo, el sistema de justicia. Como consecuencia de esto, también

\footnotetext{
1 El término alude a pensar que la violencia contra las mujeres no es vista como tal, es decir, como una vulneración de derechos, sino que aquello que las leyes nombran como "violencia contra la mujer" simplemente serían los contenidos y/o efectos naturales, propios de las relaciones entre los sexos, o de las relaciones que mantienen las mujeres con diversas esferas de acción cultural. El proceso de "naturalización", de invisibilización de la violencia y la discriminación que existen en esas relaciones no es percibida como tal porque se justifica en los estereotipos de género masculino y femenino: las cosas que les suceden a las mujeres, les suceden porque es propio, inherente a su ser mujer, a su femineidad; la propia condición social de mujer o varón opera como un justificante -consciente o inconscientemente, voluntaria o involuntariamente-, de lo que acontece, en tanto es visto como orden natural dado.
} 
pretendo hacer notar que las relaciones de desigualdad entre los sexos no se van a transformar en formas de vida dignas para las mujeres sin que haya una transformación profunda de las relaciones materiales y de nuestros sistemas de creencias históricamente sedimentados, por la cual algunos varones, que exhiben rasgos de la masculinidad dominante, necesitan oprimir y dominar a la mitad de la humanidad, en tanto mujeres, así como también a otros varones que no responden al "arquetipo viril" 2 postulado y sostenido en Occidente.

En cuanto al sentido que adquieren algunas normativas, no puedo eludir la relación necesaria entre el ejercicio del poder, el saber y las formulaciones jurídicas. Las normas tienen, sin lugar a dudas, cierta potencialidad en visibilizar la violencia estructural contra las mujeres así como cierta capacidad en materia de promoción de derechos, de prevención y reparación pero también tienen su límite. Este límite, al cual entiendo estructural y propio del Derecho ${ }^{3}$, en el Estado moderno, debe ser desnudado y exhibido con el fin de que queden habilitados otros caminos en la construcción de políticas culturales que disminuyan la violencia, promuevan la equidad y la concepción de sujetos jurídicos, sea inclusiva de las experiencias de vida de las mujeres y de las características que integran lo considerado femenino, es decir, que nos permita salirnos del lugar de otredad degradada ${ }^{4}$.

Ciertas lecturas emparentadas con el liberalismo político que conceden potencialidad al Derecho en cuanto al establecimiento de una legalidad protectora en contra de la arbitrariedad y el abuso, permitirían pensar que las situaciones de violencia contra las mujeres producidas por el Estado -violencia institucional según la Ley de Protección Integral-, resultan, al menos, circunstanciales, excepcio-

2 Para desarrollar el concepto de masculinidad dominante se pueden consultar, entre otros, Menjívar Ochoa (2004) y Boscán Leal (2008). Los autores refieren a la construcción de la masculinidad dominante centrada en el varón de raza blanca, heterosexual, considerado superior a la mujer, sujeto de su propio deseo, activo, con cualidades como la agresividad, fortaleza, libertad, capacidad de poder y dominio, etc. Moreno (1986) desarrolla el concepto de "androcentrismo" y refiere que el "arquetipo viril" involucra algunos aspectos relativos a los varones adultos, con estatus de "marido" y con cualidades propias de la figura del guerrero - virilidad, coraje, valentía.

3 Entendido como conjunto de normativas, instituciones u organismos que las aplican, así como las prácticas judiciales.

4 Para ampliar este aspecto de la relación del Derecho con las mujeres o lo femenino ver Olsen (2009). 
nales y, en el mejor de los casos, fracasos o negación de las leyes. $\mathrm{Mi}$ entendimiento acerca de la reproducción o producción de violencia contra las mujeres ejecutada a través de variadas prácticas estatales, por diversos agentes y con distinta responsabilidad, no suponen un apartamiento negligente o dotado de impericia de los mandatos legales -sin negar que esto también está presente-, o que la violencia estatal contra las mujeres acontece porque los agentes, a sabiendas, rechazan las prescripciones normativas y en consecuencia se perpetran irregularidades respecto al marco de actuación señalado por las leyes protectoras. No se puede negar que si las leyes prescriben hacer una cosa y no se hace, o se hace lo contrario, toda la teoría jurídica y toda ideación racional que cualquier persona pudiera hacer, efectivamente indicarían que hay una irregularidad, una desviación tomando como parámetro lo que el mandato legal indica que se debe hacer.

La finalidad de este artículo no es poner en evidencia la discordancia entre lo que dicen las leyes y lo que pasa en la realidad, haciendo notar que algunos agentes estatales cometen flagrantes transgresiones a las normas. Sí, las cometen, contravienen las leyes, no obstante, el problema central de este estudio no radica en ese tópico sino en la actuación que desempeña el Derecho, la $\mathrm{Ley}^{5}$, en nuestras sociedades respecto de la eliminación de la violencia contra las mujeres, las limitaciones de éstas frente a una estructura cultural compleja donde el modelo de humanidad preponderante coincide con los intereses, las necesidades y las experiencias de vida que integran la concepción dominante de la masculinidad y que coinciden con la de ciertos varones en particular ${ }^{6}$.

Las referencias teóricas que siguen sobre la noción de la Ley y su actuación en las formaciones estatales de Occidente no agotan las posibilidades de análisis del rol del Estado sobre sus obligaciones en la eliminación de la violencia contra las mujeres ya que, de arranque, la eficacia de las normas como garantía del Derecho a una vida libre

\footnotetext{
5 Utilizo "Ley", a los efectos de este trabajo, como la legalidad vigente en un Estado determinado y que incluye las normas nacionales e internacionales en materia de protección de derechos subjetivos y de derechos humanos.

6 Para desarrollar este aspecto ver, entre otros, Olsen (1994); Mackinnon (1995); Laurenzo, Maqueda y Rubio (2009).
} 
de violencia ${ }^{7}$ no pueden ser pensadas sin las políticas públicas y culturales que necesariamente deben acompañarla, cuestión ésta que aquí no es abordada.

Ingresando, entonces, en las observaciones de las relaciones entre la violencia y la dominación que se ejercen a partir de los usos del Derecho, acuerdo con Foucault cuando señala que el sistema del derecho "son los trámites permanentes de relaciones de dominación y de técnicas de sujeción polimorfas. El derecho es visto, creo, no del lado de una legitimidad a establecer, sino del de los procedimientos de sujeción que pone en funcionamiento" (1993:26). Siguiendo este planteo, se puede advertir que las relaciones de dominación entre los sexos, también están posibilitadas por el derecho, en tanto instrumento que "hace funcionar relaciones que no son relaciones de soberanía sino de dominación", entendiendo por dominación no "tanto la dominación de uno sobre otros o de un grupo sobre otros, sino las múltiples formas de dominación que pueden ejercerse dentro de la sociedad" (Foucault, 1993:25).

En este sentido, cabe traer como aporte el planteo de Poulantzas respecto de pensar la Ley no como aquello que se opone a la violencia, noción que según entiende se corresponde con una "concepción jurídico-legalista del Estado, la de la filosofía política del Estado burgués” (Poulantzas, 1986:87), sino más bien lo contrario. Para este filósofo, el binomio o la "escisión entre ley y violencia es falsa" porque "la ley ha acompañado siempre el ejercicio de la violencia y de la represión física" (Poulantzas, 1986:88). Aunque desde posiciones muy distintas, ambos filósofos coinciden en su análisis respecto de que la violencia no sólo no está excluida de la Ley, el Derecho, sino que la violencia, la dominación forman parte de la constitución del Estado moderno.

Con un posicionamiento diverso, también encontramos sugestivos aportes de la jurista MacKinnon, quien introduce en su análisis del "Estado liberal y del legalismo liberal" la categoría de "género", en

7 Art. 3 de la Convención Interamericana para Prevenir, Sancionar y Erradicar la Violencia contra La Mujer.

8 Para este trabajo, voy a entender el concepto de género como aquellas relaciones de poder 
tanto considera al género como sistema político. Ella sostiene que las relaciones de género son relaciones de poder (MacKinnon, 1995:285) ${ }^{9}$ y las formas estatales no son neutrales a las mismas: "el Estado es masculino (...) la ley ve y trata a las mujeres como los hombres ven y tratan a las mujeres". Respecto del liberalismo político, señala que el Estado "constituye con coacción y autoridad el orden social a favor de los hombres como género, legitimando normas, formas, la relación con la sociedad y sus políticas básicas” (MacKinnon, 1995:288,289). Para esta autora, la base de la violencia contra las mujeres ejercida a través del Estado está dada porque "el poder estatal, encarnado en la ley existe en toda la sociedad como poder masculino al mismo tiempo que el poder de los hombres sobre las mujeres en toda la sociedad se organiza como poder del Estado" (MacKinnon, 1995:303).

En cuanto a los fundamentos teóricos que apoyan este trabajo tomo fundamentalmente lecturas del campo de la filosofía, de los estudios de género y de las teorías críticas del derecho. El entrecruzamiento de perspectivas y de autores/as realizado se sustenta en la visión de que la construcción de lo que llamamos realidad social se sostiene en la compleja trama de discursos y prácticas que se originan en distintos campos del saber y del hacer social que convergen produciendo sentidos, realidad, cosmovisiones, etc. Considero que la comprensión de la histórica situación degradada de las mujeres en relación con los lugares de masculinidad dominantes, el intento de revertirla a través de normativas de derechos humanos así como el rol que juega el Estado en todo esto, no pueden entenderse desde un mismo campo del saber -por ejemplo el Derecho-, como tampoco recurriendo al método de la historia de las ideas, en tanto una progresión de la historia en tanto linealidad de acontecimientos y pensamientos. Más bien, el presente de la realidad de las mujeres podrá comprenderse entrecruzando discursos, prácticas, saberes no presentados como

constructoras de la diferencia sexual entre los individuos en tanto hombre y mujer, o masculino y femenino, ambas como categorías o formas existenciales de vida social, política y psíquica binarias y opuestas. Diferentes desarrollos del tema se pueden encontrar en Butler (2001); Rubin (1986); Scott (1993).

9 "El género es un sistema social que divide el poder. Por tanto, es un sistema político" (Mackinon, 1995:285). 
sucesión sino como rupturas, quiebres que, para explicarlos hay que ir a otros registros que no son la "historia" misma. Por ello es que en este trabajo aparecen formulaciones teóricas que pertenecen a distintas épocas y distintos registros del saber. Del mismo modo, tampoco es el contexto témporo-espacial el que da sentido a la violencia contra las mujeres, al menos no en el sentido más profundo que pretendo instalar en estas líneas ${ }^{10}$.

Por último, cabe explicitar el sentido que tiene el examen de cuatro situaciones que realizo y que involucran a niñas de distintas provincias del país. Las cuatro situaciones, aparecidas en medios de prensa en el año 2012, tienen algunos elementos relevantes que han determinado su selección: se trata de niñas y una de las formas de violencia que han atravesado proviene de agentes estatales -a la luz de la Ley de Protección Integral-, la cual aparece silenciada, invisibilizada, irrelevante y no sancionada como tal. El examen de las situaciones tiene como punto de partida la coincidencia con Foucault en cuanto a que el poder, ese poder que transita a través de los individuos y que uno de sus primeros efectos es que los cuerpos -con sus gestos, discursos y deseos- sean identificados como individuos (Foucault, 1993:27), debe ser captado "en sus extremidades, en sus terminaciones, ahí donde se hace capilar (...) sobre todo allí donde, saliéndose de las reglas del derecho que lo organizan y lo delimitan, se prolongan más allá de ellas invistiéndose en instituciones, toma cuerpo en técnicas y se da instrumentos de acción material que pueden también ser violentas" (Foucault, 1993:26)11. Del análisis de las

\footnotetext{
10 Con esto no se desconoce que los contextos culturales, regionales y las épocas están ceñidas por marcaciones diferentes respecto del ejercicio de formas de dominación, de control de los cuerpos y de la sexualidad de las mujeres, etc. De hecho, la existencia de normas que en muchos países en el siglo XXI sancionan la violencia contra las mujeres marcan una diferencia fundamental con el siglo XIX y los anteriores porque permiten nombrar de otra manera la constitución y efectos de las relaciones entre los sexos. Sin embargo, ni las normas ni los sistemas de jurisdicción universal o regional (ONU y OEA) han frenado la escalada de violencia cruel que, por ejemplo, mercantiliza objetalizando los cuerpos de niñas, niños y adolescentes para el consumo sexual de varones adultos. Por todo esto, en este trabajo no cobra importancia el análisis sucesivo de teorías o de la aparición de las normas, como si hubiera un desarrollo progresivo de las mismas, así como tampoco el contexto local en el cual se desarrollan las cuatro situaciones particulares de violencia que se trabajan.

11 Para ejemplificar su proyecto de trabajo el autor refiere a su análisis de la prisión y de la constitución del delincuente, no a partir de los reglamentos o de los códigos, sino de la aplicación de los aparatos de castigo. Así, señala que ha tratado de tomar "el poder en el extremo menos jurídico de su ejercicio".
} 
situaciones presentadas, pretendo mostrar cómo se construyen individuos mujeres-niñas en condiciones degradadas de humanidad respecto del sujeto jurídico proclamado por el Derecho. En términos de Foucault, podría decir que no hay niñas, en tanto sujetos de derecho, a las cuales el poder estatal viene a doblegar o despedazar sino que, más bien, esas instancias materiales, esos cuerpos infantes, esas niñas son sujetadas por discursos y prácticas de agentes estatales, entre otros, que las constituyen como individuos que no importan ${ }^{12}$ en la conformación del sujeto de derecho.

\section{El camino hacia la protección formal}

A continuación expondré sucintamente algunas normativas que tienen como antecedente la histórica lucha del movimiento de mujeres a nivel internacional y nacional y que abordan, de una manera u otra, la protección del derecho de las mujeres a una vida sin violencia entre otros. Esto apunta a posibilitar la comprensión de la denominada violencia institucional, violencia perpetrada o tolerada por el Estado y a advertir las responsabilidades que éste asume con relación a la violencia contra las mujeres.

La Convención sobre la Eliminación de todas las formas de Discriminación contra la Mujer (CEDAW) ${ }^{13}$ determina que la expresión "discriminación contra la mujer" denotará toda distinción, exclusión o restricción basada en el sexo que tenga por objeto o por resultado menoscabar o anular el reconocimiento, goce o ejercicio por la mujer, independientemente de su estado civil, sobre la base de la igualdad del hombre y la mujer, de los derechos humanos y las libertades fundamentales en las esferas política, económica, social, cultural y civil o en cualquier otra esfera" (Art. 1). A través de la Convención, los Estados partes se comprometen a seguir una política

12 Este término pertenece a Judith Butler y será retomado más adelante.

13 Aprobada por el Estado argentino por Ley $N^{\circ} 24.632$ en el año 1996. 
encaminada a eliminar la discriminación ${ }^{14}$. También contamos con la Convención Interamericana para Prevenir, Sancionar y Erradicar la Violencia contra la Mujer ${ }^{15}$, conocida como Convención de Belem do Pará, la cual entiende por "violencia contra la mujer" señalando que es "cualquier acción o conducta, basada en su género, que cause muerte, daño o sufrimiento físico, sexual o psicológico a la mujer, tanto en el ámbito público como en el privado" (Art. 1). Las formas de violencia que contempla son la física, sexual y psicológica y los ámbitos en que se pueden perpetrar son "la familia o unidad doméstica o en cualquier otra relación interpersonal", en "la comunidad y sea perpetrada por cualquier persona (...), así como en instituciones educativas, establecimientos de salud o cualquier otro lugar" y la "que sea perpetrada o tolerada por el Estado o sus agentes, donde quiera que ocurra” (Art. 2; negritas nuestras). Para erradicarlas los Estados se comprometen en adoptar "políticas orientadas a prevenir, sancionar y erradicar dicha violencia"16.

Ambas normativas determinan obligaciones para los Estados relativas tanto a la abstención de ejercer violencia y discriminación como a diseñar e implementar políticas públicas integrales para la protección, asistencia y reparación de los daños provocados por la violencia y la discriminación. En cuanto a las normas que contemplan derechos especiales por la condición de niña o niño, Argentina ha incorporado a su derecho interno la Convención sobre los Derechos del Niño $(\mathrm{CDN})^{17}$, la cual obliga a los Estados a asegurar a la infancia el goce

14 Estas obligaciones contemplan, entre otras medidas, "la protección jurídica de los derechos de la mujer y garantizar, por conducto de los tribunales nacionales competentes y de otras instituciones públicas, la protección efectiva de la mujer contra todo acto de discriminación"; "abstenerse de incurrir en todo acto o práctica de discriminación contra la mujer y velar porque las autoridades e instituciones públicas actúen de conformidad con esta obligación”.

15 Aprobada por el Estado argentino por Ley No 24.632 en el año 1996.

16 La Convención, entre otras cosas, obliga a los Estados a "abstenerse de cualquier acción o práctica de violencia y velar por que las autoridades, sus funcionarios, personal y agentes e instituciones se comporten de conformidad con esta obligación"; "actuar con la debida diligencia para prevenir, investigar y sancionar la violencia contra la mujer”; “establecer procedimientos legales justos y eficaces para la mujer que haya sido sometida a violencia, que incluyan, entre otros, medidas de protección, un juicio oportuno y el acceso efectivo a tales procedimientos"; "establecer los mecanismos judiciales y administrativos necesarios para asegurar que la mujer objeto de violencia tenga acceso efectivo a resarcimiento, reparación del daño u otros medios de compensación justos y eficaces” (Art. 7).

17 Aprobada por el Estado argentino por Ley Nº 23.849 en el año 1990. 
de los derechos enunciados en la normativa con independencia de "la raza, el color, el sexo, el idioma, la religión, la opinión política o de otra índole, el origen nacional, étnico o social, la posición económica, los impedimentos físicos, el nacimiento o cualquier otra condición del niño, de sus padres o de sus representantes legales” (Art. 2)18.

El camino de reconocimiento jurídico internacional a través de tratados de derechos humanos incorporados por Argentina al ordenamiento interno prosiguió la sanción de leyes nacionales. En el año 2009 fue sancionada la Ley de Protección Integral No 26.485 la cual establece diversos tipos y modalidades de violencia, tomando para este trabajo sólo la denominada "violencia institucional" definida como "aquella realizada por las/los funcionarias/os, profesionales, personal y agentes pertenecientes a cualquier órgano, ente o institución pública, que tenga como fin retardar, obstaculizar o impedir que las mujeres tengan acceso a las políticas públicas y ejerzan los derechos previstos en esta ley" (Art. 6, inc. b). En relación con la protección de la infancia, contamos con la Ley de Protección Integral de los Derechos de las Niñas, Niños y Adolescentes, $\mathrm{N}^{\circ} 26.061$ del año 2005, la cual reafirma el sentido de la CDN respecto de la "máxima exigibilidad" de los derechos reconocidos a niños y niñas, fundándose en el "principio del interés superior del niño" (Art. 1). Asimismo, es pertinente mencionar dos figuras del Código Penal (CP) argentino que refieren a la tipificación del delito de violación sexual y a las excepciones a la regla general de penalización del aborto, conocidas como abortos no punibles. En cuanto al alcance del delito de violación $^{19}$, se reprime con pena de prisión a quien abusare sexualmente de persona menor de trece años, hubiere mediado o no acceso carnal. La ley entiende que siempre hay abuso sexual cuando se trata de personas menores de trece años porque se presume que no es posible la

18 En el mismo sentido, el Pacto Internacional de Derechos Económicos, Sociales y Culturales; el Pacto Internacional de Derechos Civiles y Políticos y la Convención Americana sobre Derechos Humanos establecen la obligación de adoptar medidas especiales de protección.

19 Código Penal Argentino. Art. 119. "Será reprimido con reclusión o prisión de seis meses a cuatro años el que abusare sexualmente de persona de uno u otro sexo cuando, ésta fuera menor de trece años o cuando mediare violencia, amenaza, abuso coactivo o intimidatorio de una relación de dependencia, de autoridad, o de poder, o aprovechándose de que la víctima por cualquier causa no haya podido consentir libremente la acción”. 
existencia de consentimiento, por lo que no hay "relaciones sexuales" sino abuso sexual. En relación con los derechos reproductivos, el art. 86 inc. 2 del CP plantea que no es punible el aborto practicado a una mujer cuyo embarazo proviene de una violación ${ }^{20}$.

Las normativas observadas contribuirán a analizar la perpetración por parte del Estado de violencia, discriminación, falta de acceso a la justicia y, en general, incumplimiento de la Ley en las cuatro situaciones trabajadas, y desentrañar algunas de las tensiones existentes señaladas más arriba.

\section{El camino hacia la mera humanidad}

Aquí se exponen elementos de las cuatro situaciones que involucran a niñas que permiten un análisis de los entrecruzamientos de discursos y prácticas institucionales. Los datos fueron relevados de medios de comunicación y se ha tomado lo relativo a las intervenciones de agentes estatales, por lo que no se analizan los posibles encadenamientos de violencias múltiples, ni tampoco el formato con que los medios de comunicación construyeron o presentaron la noticia.

\section{Situación 1: Provincia de Entre Ríos. Enero y julio de 2012}

En enero de 2012 se conoce que una niña de 11 años de la localidad de General Campos, Entre Ríos, estaba embarazada; a las doce semanas de embarazo concurre a un servicio público de salud solicitando el acceso al aborto no punible contemplado en el art. 86 inc. 2 del CP. El Hospital Masvernat se niega a llevar la práctica e informa que la niña "es apta físicamente para seguir con su estado de gravidez"; se le dice a la madre que tiene que realizar la denuncia

20 Código Penal Argentino. Art. 86. "Incurrirán en las penas establecidas en el artículo anterior y sufrirán, además, inhabilitación especial por doble tiempo que el de la condena, los médicos, cirujanos, parteras o farmacéuticos que abusaren de su ciencia o arte para causar el aborto o cooperaren a causarlo. El aborto practicado por un médico diplomado con el consentimiento de la mujer encinta, no es punible: $1^{\circ}$. si se ha hecho con el fin de evitar un peligro para la vida o la salud de la madre y si este peligro no puede ser evitado por otros medios; $2^{\circ}$. si el embarazo proviene de una violación o de un atentado al pudor cometido sobre una mujer idiota o demente. En este caso, el consentimiento de su representante legal deberá ser requerido para el aborto". 
policial por la violación que fuera cometida por un joven de 17 años. Se realiza la denuncia y la familia recurre a la justicia solicitando la autorización judicial para llevar adelante la interrupción del embarazo. El juez, pese a la innecesariedad de su intervención dado que la autorización judicial no es requisito establecido en el art. 86 del $\mathrm{CP}$, toma medidas dilatorias para retardar la (ilegal) resolución de la autorización y lograr que la práctica se torne imposible, dado el estado avanzado de la gestación. Una de estas medidas fue citar a diversas audiencias a la niña, a la madre, incluso al padrastro de la niña. En este tramo del proceso, determinados grupos, en general de índole religiosa que suelen manifestarse en contra de los derechos reproductivos de las mujeres, intimidaron y presionaron a la madre para que retire el pedido de aborto no punible. Entre tanto, el ministro de Salud, Hugo Cettour, en una entrevista radial señaló que "una vez que la niña tuvo su primera ovulación, está en condiciones físicas para sostener un embarazo. La naturaleza es sabia, la menstruación prepara al cuerpo. Quizá habrá que tener cuidados al momento del parto y programar una cesárea”. En el mes de julio la gestación culminó en una cesárea de urgencia, quedando la niña bajo tratamiento psicológico. Según se conoció por los medios de prensa, el municipio les otorgó un terreno y una vivienda en General Campos, para que vivan allí la nena y su familia ${ }^{21}$.

\section{Situación 2: Provincia de La Pampa. Agosto de 2012}

Una niña de 11 años, internada en los Mini Hogares de General Pico, La Pampa, fue víctima de agresión física y verbal por parte de una celadora. A partir de este hecho, una funcionaria del Ministerio de Bienestar Social responsable de los hogares, presentó una denuncia en la fiscalía para que se investigue el episodio ocurrido en el establecimiento. Tras esta denuncia, el fiscal inició la investigación

21 “Comenzamos bien. Responsabilidad, profesionalismo, respeto, profunda humanidad, demostró el equipo interdisciplinario del Hospital Delicia Concepción Masvernat de Entre Ríos y el Ministro de Salud de esa Provincia, Dr. Hugo Cettour, ante el hecho de la pequeña de 11 años embarazada de otro menor, en General Campos (Entre Ríos - Argentina)”. Link: http://www.vientredecristal.com 12012_01_01_archive.html. Este es un sitio web que se manifiesta contra los derechos de las mujeres a la autonomía reproductiva. 
y ordenó secuestrar la historia clínica de la niña encontrando que la misma tenía colocado un dispositivo intrauterino (DIU) el cual había sido autorizado por un juez de un Juzgado del Menor y la Familia de Santa Rosa. Según se pudo relevar, aparentemente el juez resolvió que se le coloque el DIU a partir de los pedidos efectuados por personal médico y asistentes sociales; incluso hasta el asesor de menores habría avalado la colocación de ese método anticonceptivo. El personal que trabaja en el hogar informó que la niña era presuntamente abusada sexualmente cuando se "escapaba" del hogar; sin embargo, nunca se radicó ninguna denuncia penal por esas violaciones. El fiscal, considerando que el testimonio de la víctima era fundamental, ordenó que se le tomara testimonio a través de la Cámara Gesell el cual no se pudo realizar porque la niña, llamativamente, fue trasladada a un hospital psiquiátrico de la ciudad bonaerense de Luján. La decisión se fundó en un informe del hospital que "aconsejó su internación debido a alteraciones psiquiátricas" lo cual significó la frustración de la investigación penal.

\section{Situación 3: Provincia de Santa Fe. Septiembre de 2012}

En septiembre de 2012 se conoció que una niña de 12 años de la localidad de Carcarañá tuvo una beba por cesárea en un hospital de Rosario. A partir del impacto que tuvo la noticia le realizaron entrevistas radiales al subdirector del hospital quien manifestó: "Es una nena de 12 años que vino esta mañana (...) y tuvo una beba en perfecto estado por cesárea (...) están bien, tanto ella como la beba (...)". Ante la pregunta del periodista sobre el origen del embarazo, responde: "Es producto de su relación con su parejita (...) Me encontré con una situación muy exitosa porque tuvo un embarazo controlado, tuvo trabajadoras sociales que la apoyaron, tuvo psicólogos y la verdad es que me encontré con una situación bastante buena”. En relación con esto, agrega que "más allá de lo llamativo que significa que alguien tenga una beba a los 12 años, desde el punto de vista médico me encontré con una situación bastante bien contenida y elaborada por psicólogos, trabajadores sociales, obstetras, neonatólogos”. Consultado sobre la edad que tienen en general las mujeres parturien- 
tas, el subdirector señaló que "es cierto que la edad de las madres en la población hospitalaria es menor que la que uno puede ver en otros efectores (...) pero 12 años es bastante llamativo (...) en este caso especial es una caso que me parece no merece preocupación más que la que ya se le ha dado y cómo se la ha contenido" (negritas nuestras)22.

\section{Situación 4: Salta. Octubre de 2012}

En octubre de 2011 el padre de una niña de 9 años denunció al propietario del transporte escolar que la llevaba a la escuela porque, según el relato que le hiciera, un día luego de retirarla de la institución escolar, el chofer le pidió que se sentara a su lado, "la tomó de la mano y le pidió que se parara y al hacerlo le tocó la cola, las piernas y los pechos". Se consigna también que, "en otras oportunidades, el chofer intentó besarla en la boca". El 15 de octubre de 2011 se presentó otra denuncia por otra niña de 10 años contra el mismo chofer porque "hacía pasar a la niña al asiento de adelante, le agarraba la mano y le tocaba la pierna izquierda". Se testimonió que la niña le sacaba la mano, "pero que el hombre insistía y volvía a manosearla" ${ }^{23}$. Se da intervención al Cuerpo de Investigaciones Fiscales (CIF) cuya titular, en octubre de 2012, presenta un escrito ante la Fiscalía Correccional $\mathrm{N}^{\circ} 7$ con diversas opiniones cargadas de discriminación sexista que ubican a las niñas no como víctimas de la violencia sexual sino como instigadoras de la misma, como objeto y no como sujeto de derechos. Como parte de la investigación el CIF entrevistó a las víctimas, a otras niñas compañeras de la escuela y a sus padres, llegando a la conclusión que el chofer "tiene buen concepto por parte de la mayoría de los entrevistados". Agrega el informe del CIF que "por otra parte y siguiendo el análisis de las menores en-

22 Link audio en "Una nena de 12 años de Carcarañá dio a luz a una beba en el Hospital Centenario". La Capital, 21 de septiembre de 2012 [en línea: 16/02/13] Disponible en: www.lacapital.com.ar/ la-ciudad/Una-nena-de-12-aos-dio-a-luz-a-una-beba-en-el-Hospital-Centenario-20120921-0042. html. Ver también: "Una nena de 12 años dio a luz a una beba en el Centenario". Rosario3.com. 21 de septiembre de 2012 [en línea: 16/02/13] Disponible en: www.rosario3.com/noticias/noticias. aspx?idNot=118530\&Una-nena-de-12-a\%C3\%B1os-dio-a-luz-a-una-beba-en-el-Centenario

23 “Con 9 años 'muestra un cuerpo que puede ser objeto de deseo'. El Tribuno. 29 de octubre de 2012 [en línea: 13/02/13] Disponible en: www.eltribuno.info/salta/217501-Con-9-anos-muestra-un-cuerpoque-puede-ser-objeto-de-deseo.note.aspx. 
trevistadas, se pudo observar que con las menores que tuvo conflictos (...) son de una fisonomía diferente a las demás niñas (...) por cuanto las mismas presentan una contextura más desarrollada que las demás niñas" (cursivas nuestras) ${ }^{24}$. Una de las víctimas, la niña de nueve años, expresa el informe "se muestra como una niña extrovertida y desenvuelta" y "relata los hechos sin mostrar signos de angustia (...) ni sentimientos de culpa (...) Finalmente puede decirse que no se muestra como niña, sino que se ubica más bien en un lugar de mujer, mostrando un cuerpo desarrollado que puede llegar a ser objeto de deseo" (negritas nuestras) ${ }^{25}$.

Cavarero afirma que la infancia constituye "el paradigma primario de todo discurso sobre la vulnerabilidad, siendo con mayor razón y al mismo tiempo también el paradigma primario de todo discurso sobre el inerme" (2009:59). La idea de "inerme" remite a la condición de quien, atacado por otro, no tiene armas para defenderse. Es una condición de pasividad en la cual se sufre una violencia de la cual no se puede escapar y no se puede responder; "toda la escena está desequilibrada por una violencia unilateral. No hay simetría, ni paridad ni reciprocidad (Cavarero, 2009:59)". El ser inerme del niño/niña no depende de las circunstancias; "la infancia no es una circunstancia, es una condición, o sea, el modo esencial con que el ser humano hace su ingreso al mundo y lo habita por algún tiempo" (Cavarero, 2009:59) ${ }^{26}$. Es esta condición de indefensión la que hizo

24 "La culpa es de los otros". El Tribuno. 01 de noviembre de 2012 [en línea: 24/12/12] Disponible en: www.eltribuno.info/salta/218596-La-culpa-es-de-los-otros.note.aspx.

25 "Con 9 años "muestra un cuerpo que puede ser objeto de deseo". El Tribuno. 29 de octubre de 2012. Op. cit. Ver también: "Para la Justicia salteña, una nena de 9 años "puede ser objeto de deseo"”. Infobae. 29 de octubre de 2012 [en línea: 21/12/12] Disponible en: www.infobae.com/notas/678372Para-la-Justicia-saltena-una-nena-de-9-anos-puede-ser-objeto-de-deseo.html. Ver también: "Relativizan el abuso a una menor por tener un "cuerpo que puede ser objeto de deseo". Perfil.com. 30 de octubre de 2012 [en línea: 21/12/12] Disponible en: www.perfil.com/contenidos/2012/10/29/noticia_0033. html

26 Es oportuno despejar un aspecto que ciertos discursos sociales e institucionales suelen presentar de manera confusa. Las mujeres, como tales, no constituimos un grupo vulnerable. Las mujeres somos, al menos, la mitad de la humanidad, no un grupo. Por otro lado, la vulnerabilidad, entendida como debilidad o fragilidad, no es un aspecto propio, ínsito del ser humano mujer, no es una posición o -en términos de Cavarero- una condición intrínseca a la constitución de la identidad femenina sino más bien cualidades que la historia del pensamiento ha atribuido a las mujeres, del mismo modo que atribuyen a los varones -o a lo masculino- las cualidades de fortaleza, firmeza y vigor. La vulnerabilidad está en 
existir a las normativas que plantean la especial protección de niñas y niños en tanto tales, con independencia de su sexo. La CDN señala que, tal como ocurrió en las cuatro situaciones vistas, cuando tomen intervención instituciones públicas o privadas, el sistema de justicia, organismos administrativos y órganos legislativos se debe tener una consideración primordial a que se atenderá el interés superior del niño y de la niña.

En dos de las situaciones mencionadas -Entre Ríos y Santa Fe- las niñas fueron violadas y en otra, según la creencia de los agentes que estaban a su cuidado, la niña lo estaba siendo -La Pampa. Sin embargo, pese a la responsabilidad profesional que se tiene de denunciar o anoticiar cuando se conoce la comisión de un delito ${ }^{27}$, en dos de las tres situaciones la violencia sexual infantil no sólo no aparece expuesta como tal sino que se la naturaliza. En el caso de Santa Fe, el acto de violación queda descartado por la autoridad del efector de salud, señalando que la niña de 12 años tuvo relaciones con su "parejita" de 21 años, según la información dada por su madre ${ }^{28}$. Hasta tal punto se encuentra naturalizada esa situación que el subdirector del hospital sólo se refirió a su condición de parturienta, señalando "que me parece no merece preocupación más que la que ya se le ha dado y cómo se la ha contenido", refiriéndose a la contención de diversos profesionales, negando o desconociendo que siempre hay violación cuando se trate de personas menores de 13 años, lo cual debió ser denunciado.

En la situación de La Pampa, la violencia sexual reiterada a la que se veía expuesta la niña cuando aparentemente se iba del hogar se naturalizó con la decisión de incorporarle un DIU. La preocupación

\footnotetext{
las condiciones materiales y simbólicas en las que las mujeres desarrollamos nuestras vidas; vulnerables y endebles son, por inexistentes, insuficientes y muchas veces inadecuadas, las políticas públicas y culturales para promover los derechos y condiciones de vida digna.

27 La obligación de denunciar un delito conocido en razón de las funciones que ejercen agentes del Estado, profesionales de la salud, de servicios sociales, etc. está contemplada en diversas normativas de fondo (Código Penal), en los Códigos procesales penales de las provincias, en la Ley nacional 26.061 y las leyes de protección de la infancia de cada jurisdicción provincial.

28 La mujer aseguró que se dio cuenta del embarazo de su hija "después de los primeros vómitos". Hasta ese entonces no sabía que estaba en pareja. Sobre el padre de su nieta, contó que es un joven de 21 años a quien conoce "de chiquitito". "Una nena de 12 años dio a luz a una beba en el Centenario". Rosario3.com. Op. Cit.
} 
de los operadores estatales no era que la niña fuera violada sino que no quedara embarazada ya que, es probable que hayan hecho esta deducción: un embarazo haría visible la falta de cuidado y desprotección de la institución hacia la niña a quien debían, legalmente, cuidar y proteger.

En la situación de Entre Ríos la denuncia penal de la violación aparece como "requisito"-aunque en realidad funcionó como valla-, para llevar adelante la práctica del aborto no punible contemplado en el art. 86 inc. 2 del CP. La denuncia no aparece indicada por los agentes de justicia como el resultado de la responsabilidad legal que se tienen frente a una víctima de violación sexual menor de edad. Aun así, con denuncia penal, hubo varios obstáculos provenientes del Estado y de sectores que ejercieron presión en la decisión de la familia para que retire la solicitud de la práctica de aborto legal; decisión que, por otra parte, fue bien recibida por el juez civil. Dirá Foucault que las prácticas judiciales son algunas de las formas que nuestra sociedad emplea "para definir tipos de subjetividad, formas de saber" y las relaciones entre el individuo y la verdad (1991:17).

En efecto, tanto la decisión del juez entrerreriano respecto de hacerle lugar al pedido de interrupción del embarazo el cual, como se indicó, no sólo es innecesario sino ilegal así como la toma de una serie de medidas dentro del proceso judicial que dilataban la "autorización", han resultado formas productoras y reproductoras de subjetividad femenina ligadas a la maternidad. El posicionamiento judicial pareciera mostrar un funcionamiento a partir de un saber estereotipado sobre las mujeres que, obviamente, no se hace explícito y que es el de que las mujeres deben parir; es decir, de la maternidad a toda costa -y a cualquier costo- en tanto se trataría de una función natural y obligada de todo ser humano mujer.

A través de una interpretación que no exige demasiada sagacidad, es evidente que para estos discursos profesionales y prácticas institucionales, la maternidad es una condición natural de las mujeres, independientemente de su edad. Lejos de ser entendida y protegida como una elección es presentada como un devenir natural del cuerpo. Así lo expresó con claridad el Ministro de Salud de Entre Ríos: "la 
naturaleza es sabia, la menstruación prepara al cuerpo". Ser madre, desarrollar ese rol, se sostiene y reduce sólo y exclusivamente a la posibilidad biológica de concebir, engendrar y parir. El subdirector del hospital rosarino -Santa $\mathrm{Fe}$ - giró todo su relato en el "éxito" de la cesárea y en el "buen estado de salud" que tenían la niña y la beba. ¿Cuál es el concepto de salud que tiene este profesional? Evidentemente no el criterio de la Organización Mundial de la Salud que data de 1948 por el cual se concibe a la salud como el bienestar físico, psíquico y social y no la ausencia de enfermedades. Entre una niña de 12 años y un adulto de 21 años difícilmente puede haber una relación de "parejita"; entre 12 y 21 años hay más bien una relación des-pareja que conlleva desigualdad y abuso, propio de un contacto sexual entre una niña y una persona mayor de edad. Sin embargo, para lo que en el sistema legal de Argentina es un delito, para el funcionario parece que a los "12 años (sólo) es bastante llamativo".

Revisando algunos conceptos del pensamiento filosófico y político de la Antigüedad se puede observar que los mismos están presentes en relación con la caracterización de la diferencia sexual -mujer/varón-y los elementos que integran los géneros femenino y masculino. Platón en su diálogo Teetetes, hace decir a Sócrates que existe una similitud entre el oficio de las parteras y el oficio que el mismo Sócrates debe desempeñar, de acuerdo al mandato de los dioses. Sócrates compara su oficio al cual estaba predestinado con el de su madre Fenerete, partera. Mientras que la tarea de las parteras es ayudar a parir con el cuerpo otros cuerpos, su misión en el mundo es la de ayudar a los varones al alumbramiento de las almas, es decir que las almas puedan parir ideas. El problema se presenta cuando Sócrates, en versión platónica, se distancia de dicha analogía en dos aspectos cruciales que se han inscrito en todo el andamiaje jurídico de occidente: el oficio de las parteras es muy inferior al mío ${ }^{29}$ porque las parteras no

29 "Sócrates. Tal es, pues, el oficio de parteras o matronas, que es muy inferior al mío. En efecto, estas mujeres no tienen que partear tan pronto quimeras o cosas imaginarias como seres verdaderos, lo cual no es tan fácil distinguir, y si las matronas tuviesen en esta materia el discernimiento de lo verdadero y de lo falso, sería la parte más bella e importante de su arte” (Platón, 1871:171). 
tienen el discernimiento de lo verdadero y lo falso. Esto responde a la separación y jerarquización que realiza Platón respecto del cuerpo y el alma: el cuerpo, en tanto materia, efímera, sujeta a la corrupción y a la mortalidad es absolutamente inferior al alma, la cual revestiría la calidad de perfecta, inmortal e incorruptible. El alma es superior al cuerpo, en consecuencia, parir con el alma ideas es superior a parir con el cuerpo -otros cuerpos. El otro aspecto donde vuelve a aparecer la diferencia jerarquizada es en razón del sexo, cuando Sócrates (Platón), expresa que el oficio de partear ideas sólo se puede ejercer sobre los hombres ${ }^{30}$. La mayéutica socrática -arte de parir ideas-, es decir, pensar, razonar, hacer ciencia, cabe a los varones ya que sólo ellos están dotados de razón, de la posibilidad del discernimiento entre lo que es "un fantasma, una quimera o un fruto real". "De modo que mientras que las mujeres sólo pueden concebir niños-cuerpo, carne, materia corruptible y perecedera, los varones -cabe aclarar, los varones que no son esclavos-, pueden concebir ideas-atemporales, inmateriales, eternas y absolutas" (Femenías, 2012:98). Según Butler, para que en Platón se pueda configurar el espacio integrado por aquellos seres humanamente valiosos, se necesita ineludiblemente la creación de Otros disminuidos en su capacidad de razonamiento; así nos encontramos con una zona de exclusión en la que Platón ubica a las mujeres, los esclavos, los niños y también a los animales, en tanto seres cuya naturaleza se consideran menos racionales en virtud de que están destinadas y destinados a realizar sólo tareas para la reproducción de la vida doméstica (Butler, 2002:85). Entre estas tareas, para las mujeres está la de parir criaturas.

Aristóteles expone también una configuración subjetiva diferente de los individuos según el sexo y en base a ello se derivan capacidades diferentes que concluyen en la exclusión de las mujeres del campo de la ciudadanía griega. En La Política señala que existen seres inteligentes por naturaleza que deben gobernar-ciudadanos- y que otros

30 "El oficio de partear, tal como yo le desempeño, se parece en todo lo demás al de las matronas, pero difiere en que yo le ejerzo sobre los hombres y no sobre las mujeres, y en que asisten al alumbramiento, no los cuerpos, sino las almas. La gran ventaja es, que me pone en estado de discernir con seguridad, si lo que el alma de un joven siente es un fantasma, una quimera o un fruto real” (Platón, 1871:171). Cf. Femenías (2012:24). 
seres que por naturaleza son capaces de realizar cosas con su cuerpo; éstos últimos son súbditos -simples seres humanos, individuos libresy esclavos; de tal modo, por naturaleza, están definidos la mujer y el esclavo (Aristóteles, 2000). En el pensamiento de los funcionarios de salud de Entre Ríos y Santa Fe se divisan aspectos del pensamiento de estos filósofos en relación con la idea que tienen del cuerpo y la capacidad reproductora de las mujeres.

En cuanto al posicionamiento de las/los operadores de justicia respecto del abuso sexual padecido por las niñas salteñas de 9 y 10 años, la violencia se manifiesta en la reproducción de estereotipos discriminadores hacia las mujeres revistiendo mayor gravedad por tratarse de niñas y en tanto se considera que éstas podrían merecer el abuso sexual, el cual no fue pensado por la justicia como tal sino -estremecedoramente- como un conflicto. Este conflicto para los agentes de la justicia quizá sería propio del devenir natural de los deseos masculinos presuntamente irresistibles ${ }^{31}$, que se habrían activado por la fisonomía desarrollada de las niñas; niñas que, pese a sus 9 y 10 años, no serían exactamente niñas sino adultas por sus cuerpos desarrollados. En uno de los medios de prensa relevados se señalaba que la fiscalía había solicitado la suspensión del juicio -probation- debido a la "falta de antecedentes" del acusado. Este pedido resulta congruente si se lo relaciona con las expresiones de la fiscalía en el informe en el cual se adjudica a una de las niñas ausencia de supuestos sentimientos de culpa al momento de relatar los hechos: "sin mostrar signos de angustia (...) ni sentimientos de culpa”. ¿Cómo se piensa al abuso sexual contra una mujer -niña o adulta-para suponerle sentimientos de culpa?, ¿cómo se concibe a una niña para esperar de ella sentimientos de culpa por el abuso sexual del cual es víctima? En términos jurídicos es posible deducir que si se le supone culpa es porque se le adjudica

31 La fiscalía hacía referencia al buen concepto del acusado asignando una mirada provocadora en las niñas en razón de las características de su cuerpo, con la potencialidad de generar impulsos irreprimibles en los varones; impulsos justificados posiblemente en la histórica atribución cultural que se ha hecho de cierta dosis de agresividad a la sexualidad masculina pero que, en general, se correspondería con una característica de la masculinidad. Para desarrollar este aspecto, ver Osborne (2009). 
responsabilidad en la comisión de la conducta abusiva ${ }^{32}$. La descripción de la fiscalía salteña de la relación entre el cuerpo y la actitud de las niñas y del abuso sexual padecido, es la construcción que se adecua a las necesidades sexuales de los varones que la concepción dominante de la masculinidad les adjudica por naturaleza la cual, a mi entender, guarda relación con la posibilidad cultural de que los varones se apropien de los cuerpos y de la sexualidad de las mujeres como bienes de su propiedad ${ }^{33}$.

El hecho de afirmar, por ejemplo, que los varones adultos pueden tener relaciones sexuales consentidas con niñas menores de 13 años, significa no sólo renegar de la ley penal, sino prácticamente constituye una autorización-estatal-para violar. La idea de que las mujeres, adultas o niñas, son las responsables de la violencia sexual produce el borramiento mismo de la violencia y que conforma la acción como tal así como la consecuente responsabilidad en la misma; esto sea quizá lo que permita traducir esa violencia en un idioma que la neutralice: tener relaciones con la pareja, ser objeto de deseo y que este deseo genere un conflicto o colocar un DIU para prevenir los embarazos de una niña a la que se la está violando. Se observa entonces cómo la construcción especial de los cuerpos y de la sexualidad de las mujeres en el marco de la conformación de la relación binaria de los sexos es reforzada por las prácticas judiciales, en este sentido que se ha señalado que el "derecho redefine la experiencia de la mujer" (Bodelón, 2009:237), del mismo modo que define y redefine la experiencia de los varones, aunque sin nombrar directa y específicamente los términos de esa definición. Frente a determinadas agresiones vividas por las mujeres, el proceso penal activa en la conciencia de los operadores del derecho las ideas sobre los comportamientos que se consideran apropiados de acuerdo al género de las personas, los sentimientos y

32 Para ampliar este aspecto ver Osborne (2009). Los argumentos y justificantes existentes en las prácticas judiciales responsabilizando a las mujeres de haber provocado la violencia masculina -sexual o no-, son habituales en muchos países occidentales. Se pueden leer algunas sentencias penales de tribunales penales de distintas partes del mundo en Observatorio de Sentencias Judiciales. Disponible en: http://www.articulacionfeminista.org.

33 Ver Rubin (1986). Para ampliar las relaciones entre la violencia sexual y justicia penal, ver Bovino (2000). 
actitudes que serían propios de lo masculino y lo femenino; así, con todo este bagaje conceptual o ideológico y desde una supuesta neutralidad de género -entre otras neutralidades- se imparte justicia en el mismo acto en que opera una (re)producción de sujetos con género.

Las ideas sobre la sexualidad y el cuerpo de las mujeres pueden ser rastreadas en varias líneas de trabajo, una de ellas es el intercambio de mujeres. En su clásico texto El tráfico de mujeres, Rubin advierte que "el intercambio de mujeres" 34 realizado entre grupos de hombres, en tanto sujetos del intercambio mientras que las mujeres son el objeto a intercambiar, ha estado presente en casi toda la historia de la humanidad. "Las mujeres son entregadas en matrimonio, tomadas en batalla, cambiadas por favores, enviadas como tributo, intercambiadas, compradas y vendidas" (Rubin, 1986:111), pero lejos de ser prácticas vinculadas exclusivamente al llamado mundo "primitivo" parece que en las sociedades actuales -consideradas modernas o civilizadas- esas prácticas se vuelven más pronunciadas y comercializadas. Agrega Rubin que también hay tráfico de hombres como siervos, esclavos o alguna otra categoría social catastrófica pero no como hombres. En cambio, "las mujeres son objeto de transacción como esclavas, siervas y prostitutas, pero también como mujeres" (Rubin, 1986:111). La autora sugiere que muchas costumbres, rasgos de la personalidad actuales parecen tener mucho sentido si se miden en relación con este elemento de la cultura que durante la mayor parte de la historia ha ubicado a los varones como "sujetos sexuales -intercambiadores-y a las mujeres semiobjetos sexuales -regalos-", entre

34 La autora sugiere que el concepto de "intercambio de mujeres" es un concepto seductor y atractivo porque permite ubicar la opresión de las mujeres en la cultura y no en la biología. Sin embargo, también señala que es un concepto difícil, controvertido. Rubin (1986), retomando algunas ideas de Claude Leví-Strauss expone un par de conceptualizaciones breves del intercambio de mujeres, indicando que se trataría de una forma cultural vinculada a la conformación de las relaciones de parentesco. Los sistemas de parentesco, de manera general, incluyen ciertas formas de "propiedad" de las personas que no son derechos de propiedad exclusivos ni privados sino más derechos que algunas personas tienen sobre otras. Cómo es la situación de las mujeres en estas relaciones de parentesco es lo que demuestra la desigualdad basadas en el sexo, respecto del ejercicio de esos derechos de propiedad. Rubin sugiere que el intercambio de mujeres "es una forma abreviada para expresar que las relaciones sociales de un sistema de parentesco especifican que los hombres tienen ciertos derechos sobre sus parientes mujeres, y que las mujeres no tienen los mismos derechos ni sobre sí mismas ni sobre sus parientes hombres" (1986:112 y 113). 
las costumbres actuales menciona la "curiosa costumbre de que el padre entregue a la novia” (Rubin, 1986:111).

En su trabajo más reciente, Las esclavas del poder, Cacho afirma que el mundo está experimentando una proliferación de las "redes que roban, compran y esclavizan niñas y mujeres” (2011:13). Afirma que no hemos podido erradicar la esclavitud, por el contrario estamos viviendo en una cultura en la cual se produce la normalización del robo, la compraventa y corrupción sexual de niñas y adolescentes en todo el mundo y cuya única finalidad es convertirlas en objetos sexuales de alquiler y venta ${ }^{35}$. Cacho hace notar que en un "planeta aparentemente hipercomunicado por la tecnología, millones de esclavas resultan invisibles, y su voz carece de valor para la sociedad global, en general y para sus gobiernos en particular" (Cacho,

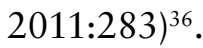

Esta privación de la condición de sujetos políticos y jurídicos plenos, condición enunciada y autoasignada por los varones para sí y autoconstituyente de lo masculino ${ }^{37}$, resulta sin lugar a dudas "deshumanizador y violento". En este sentido, Butler afirma que en el espacio de lo abyecto quedan confinados los no completamente humanos mujeres, niños, niñas, negros, entre otros-, según sus palabras, aquellos cuyos cuerpos no importan (Femenías, 2012:139). La violencia institucional en su versión estatal queda configurada al fijar, sellar a unos cuerpos, por su sexo, en el universo de la no ciudadanía, es decir, de tan sólo simples seres humanos preparadas para parir luego de su primera menstruación. Retomando la formulación de Butler ¿cuáles son los cuerpos que importan?, ¿cuáles son las vidas que merecen la tutela del Estado? Pregunto: ¿cómo se escribe "Derecho" en el marco de estas sociedades que trastocan la condición de sujeto por la condición de paridoras elevándola casi a la categoría de sagrada?

35 Para la autora la industria sexual se ha sofisticado de tal manera que ha creado un mercado que podría superar al número de esclavos africanos vendidos desde el siglo XVI hasta el XIX (Cacho, 2011:16).

36 En relación con las situaciones de conflictos armados, advierte que "el número de niñas soldados también se ha incrementado considerablemente, y muchas de ellas son utilizadas como esclavas sexuales, tal como ocurre actualmente en la República Democrática del Congo” (Cacho, 2011:284).

37 Para ampliar este tema ver Aucía (2004). 
Por mandato de la naturaleza o mandato divino, se imprimen sobre algunos cuerpos y subjetividades, designadas como mujeres al nacer, la condición de cuerpos reproductores de otros cuerpos-vidas, sin importar la edad. Dice Butler que hay vidas, "hay cuerpos que importan más que otros" (2002:49): las niñas no están incluidas allí, menos aún las niñas que viven en condiciones de exclusión social, como las niñas de Entre Ríos, la de Santa Fe y de La Pampa.

Sabemos que la filosofía positivista del siglo XIX ha sostenido que todo el hacer científico y filosófico debe fundarse en neutralidad y objetividad ideológica y valorativa, dado que esto es posible de ser alcanzado. Con estos parámetros son pensados el derecho y la actuación de las instituciones de justicia y, en consecuencia, las decisiones judiciales $^{38}$. Los diferentes estudios de la teoría crítica del derecho cuestionan este principio positivista de la neutralidad jurídica y advierten la necesidad de revisar profundamente las prácticas clásicas de la justicia, entre otras. El derecho no sólo no es neutral respecto del género -como ninguna construcción humana parece serlo- sino que el Derecho, en tanto instrumento político, tiene las marcas de sus constructores -sujetos masculinos-; esas marcas quedan invisibilizadas y es precisamente en esa invisibilidad en que reside la fuerza de su hegemonía ${ }^{39}$. Señala Bodelón que "la idea de que el derecho tiene género nos permite argumentar que las mismas prácticas significan cosas diferentes para hombres y mujeres" (2009:237). Los agentes de justicia y, en general los hacedores del derecho, operan por y a través de estereotipos de género (Cook, Cusack, 2010)40, estereotipos que se afianzan ineludiblemente en esas mismas prácticas. Cuando las creencias o ideologías de los operadores del derecho están plagadas

\footnotetext{
38 Basta con traer a la memoria la imagen gráfica con que se representa a la Justicia como una mujer con vendas en los ojos.

39 Ver, entre otros, Laurenzo, Maqueda y Rubio (2009); Birgin (2000).

40 Señalan las autoras que la estereotipación "Es el proceso de atribuirle a un individuo, características o roles únicamente en razón de su aparente membrecía a un grupo particular. La asignación de estereotipos produce generalizaciones o preconcepciones concernientes a los atributos, características o roles de quienes son miembros de un grupo social particular, lo que significa que se hace innecesario considerar las habilidades, necesidades, deseos y circunstancias individuales de cada miembro. Los estereotipos afectan tanto a hombres como a mujeres. Sin embargo, con frecuencia tienen un efecto flagrante sobre estas" (Cook y Cusack, 2010:1).
} 
de estereotipos cargados de discriminación y constituyen en sí formas de violencia o habilitan a la violencia de otros, es inevitable que esos estereotipos aparezcan consciente y/o inconscientemente dándole forma a las decisiones y a las prácticas judiciales. En el mismo gesto de producción de esa decisión o práctica judicial que se pone en marcha se reproducen los estereotipos sexistas; del mismo modo y tal como ya se adelantó, los efectos del discurso y las prácticas son productores de identidades, de subjetividad en relación con el género de las personas.

\section{¿Es posible para el Estado no producir otredad?}

Como ha señalado Bourdieu, la estructura de dominación entre los sexos se reproduce no sólo por la participación de varones singulares ejerciendo violencia sino sobre todo por la participación de instituciones como la familia, la Iglesia, la Escuela, el Estado: el principio de la perpetuación de la relación de dominación "no reside realmente, o no fundamentalmente, en uno de los lugares más visibles de su ejercicio, es decir, en el seno de la unidad doméstica (...) sino en unas instancias tales como la Escuela o el Estado -lugares de elaboración y de imposición de principios de dominación que se practican en el interior del más privado de los universos" (Bourdieu, 2002:15) ${ }^{41}$. El análisis de los discursos y prácticas judiciales y de la salud, como hemos visto, permiten viabilizar niveles significativos de invisibilización o desconocimiento de la violencia contra las mujeres, "no en tanto que individuos (jueces o abogados) insensibles, sino en cuanto constructo institucional” (Femenías, 2009:59), habilitando grandes márgenes de impunidad y de (re)producción de la misma. La compleja maquinaria puesta en marcha por agentes judiciales, de salud, administrativos, que aceptaron la violación sexual de niñas sin avizorar siquiera algún vestigio de ilegalidad, compeliendo en algunos casos a la gestación y

41 El autor menciona que ha sido, precisamente, en la unidad doméstica donde determinado discurso feminista ha concentrado sus miradas. 
el parto del embarazo resultado de una forma extrema de violencia como es la sexual, implica una renegación de la Ley que posibilita la emergencia de un sujeto de derecho y, como sugiere Legendre (1994), también un sujeto en el sentido psíquico del término.

Como fuera señalado, una de las tensiones existentes se presenta entre el modo de funcionar del Estado en relación con el derecho de acceso a la justicia para las mujeres el cual debería, según las obligaciones impuestas por las normas, poner límite a la violencia que padecen y no generarla ni reproducirla; por otro lado, para que las mujeres puedan vivir una vida libre de violencia y discriminación deben salir de las posiciones de subordinación general en las que son puestas y fijadas con argumentos basados en la biología o, sencillamente, sin argumentación porque parecería innecesaria. Sin embargo, según el sistema político y las prescripciones normativas es el mismo Estado quien tiene a su cargo la mayor responsabilidad en generar políticas para que las mujeres no sean víctimas de toda forma de violencia incluida la institucional y puedan salirse de las relaciones violentas (Femenías, 2009:56). Desde esta manera de entender el problema, Segato sugiere que las leyes, las estadísticas, registros, etc., necesitan estar acompañadas de un marco de sentido que permita percibir que para erradicar la violencia se deben reformar "los afectos constitutivos de las relaciones de género tal como las conocemos y en su aspecto percibido como 'normal'. Y esto, desgraciadamente, no puede modificarse por decreto" (Segato, 2003:133; comillas en el original). No es suscribiendo el contrato de la ley como vamos a transformar las formas de desear, las formas en que ilusoriamente encontraremos satisfacción, formas todas ellas que integran nuestro orden cultural, por eso para ella "el trabajo de la conciencia es lento pero indispensable. Es necesario removerlo, instigarlo, trabajar por una reforma de los afectos y de las sensibilidades" (Segato, 2003:133) ${ }^{42}$, trabajo que corresponde ineludiblemente a la sociedad en general. No obstante,

42 Respecto de algunos caminos para lograr este objetivo de reforma de, según sus palabras, los afectos, advierte que "Los medios masivos de comunicación, la propaganda -incluyo aquí la propaganda de la propia ley-deben ser en esto aliados indispensables. Y el trabajo de investigación y de formulación de modelos teóricos para la comprensión de las dimensiones violentas de las relaciones de género aun en las familias más normales y legales debe ser constante". 
resulta complejo pensar en instituir una Legalidad, entendida en un sentido estructurante de la cultura y más amplio que el que tienen las leyes positivas emanadas de los parlamentos, sin la intervención del Estado dado el lugar preponderante en el ejercicio del poder de transformación política precisamente por detentar el monopolio de la fuerza o de la dominación de la que habla Poulantzas y Bourdieu, o por tener a su cargo la habilitación del sistema de derecho vigente en la sociedad por el cual las personas están sujetadas, dominadas según los planteos de Foucault y MacKinnon. En palabras de Legendre, "instituir es hacer reinar lo prohibido" (1994:109) por lo que, si la Legalidad es la garante de la humanización, si ella es la que permite que ingresemos en la categoría de sujetos de derechos, "lo prohibido" también jugaría aquí un rol fundamental.

En mi opinión, la prohibición de violentar a la mitad de la humanidad basada en su condición de género o sexual, lo prohibición de la violación o del abuso sexual infantil debe ser considerada, utilizando conceptos de Legendre, una de las grandes prohibiciones que imponga una Legalidad que nos afilie a la cultura en condición de semejantes y no de otros/otras degradado/as. Las prácticas de abuso sexual infantil deben ser nombradas y sancionadas como tales, no sólo porque constituyen delitos graves, sino porque instauran una forma de sexualidad arrasadora de la subjetividad humana favoreciendo posiciones de objetalización de los seres humanos. Esto debe ir acompañado de prácticas y de la generación de marcos de comprensión, de transformación de las creencias que permitan pensar a las mujeres como sujetos de derechos, para lo cual se requeriría pensar y actuar por fuera de la relación dialéctica binaria: Uno(varón)-Otro(mujer).

Creo necesario acercar los discursos y las prácticas jurídicas, las prácticas de los hacedores de políticas públicas, en fin, todo el accionar del Estado al principio de Razón (Legendre, 1994:38) en que se funda nuestro sistema de Legalidad. Cuando digo Razón pienso en los productos de las reflexiones críticas que la humanidad ha podido realizar desde la Antigüedad occidental hasta la actualidad, en las conquistas respectos de la ampliación en los criterios racionales de una "humanidad" más inclusiva y descentrada de pensar a la razón 
como soberana, en los logros alcanzados respecto de valoraciones sobre la diversidad de experiencias en las formas de entender la propia vida y el bienestar que descarten la existencia de una presunta normalidad en el vivir. No obstante, al mismo tiempo, entiendo imprescindible revisar y reformular el criterio de racionalidad, tal como fue formulado y sostenido hasta el presente, como constructo con marcas de género masculinas de origen, congruentes con la detentación del conocimiento científico históricamente en poder de algunos varones y de una concepción dominante de masculinidad ${ }^{43}$. El principio de razón debe ser revisado y reformulado desde la categoría de género, entre otras; se caen a pedazos los fundamentos de la neutralidad de género de las construcciones culturales y hay que animarse a ver esta deconstrucción, así como al mismo tiempo hay que visibilizar que las construcciones de género llevan ínsita una desigualdad en su estructura misma que le impide a las mujeres, en tanto tales, posibilidades de desarrollo y de acceso al goce de los derechos. Quienes están política y jurídicamente en el lugar de lo Otro, de la otredad, de la diferencia desjeraquizada, también se auto perciben negativamente, o consideran que su situación se correspondería con un orden dado de las cosas. La violencia de género actúa "no sólo por medio de la limitación violenta de la autonomía personal, sino que lo hace a través de su conexión con el sentimiento de no poseer un status como sujeto de interacción moralmente igual y plenamente valioso" (Lorente Acosta, 2009:24).

¿Es posible eliminar la violencia estatal contra las mujeres basadas en su género? Esta pregunta instala un desafío, aunque me atrevo a aseverar que una manera de reducir o eliminar la violencia no es entregarse al asistencialismo piadoso como intento de borrar los efectos de una responsabilidad estatal (re)negada, tal como ocurrió con la niña entrerriana a la cual la municipalidad le da una casa más grande para que pueda vivir con su familia. Por último, insisto en la necesidad de hacer valer la función del límite (Legendre, 1994:124), hacer

43 Para ampliar este aspecto de las marcas de género masculino en los constructos científicos y filosóficos ver Fox Keller (1991). 
prevalecer lo prohibido y aplicar las sanciones que la transgresión de lo prohibido conlleva en materia de graves vulneraciones a los derechos humanos, más aún cuando esas transgresiones provienen de quienes están en la posición política de sancionar la transgresión.

\section{Referencias bibliográficas}

ARISTÓTELES. La Política. Madrid, Alba, 2000.

AUCÍA, A. "¿Adónde están las mujeres? Los derechos humanos desde una perspectiva de género", en: Zona Franca. Año XII, No 13, Revista de la Facultad de Humanidades y Artes, Universidad Nacional de Rosario, 2004. pp. 36-41.

BIRGIN, H. (Comp.). Las trampas del poder punitivo. El género del Derecho Penal. Buenos Aires, Biblos, 2000.

BODELÓN, E. "La violencia contra las mujeres y el derecho no-androcéntrico: perdidas en la traducción jurídica del feminismo", en: LAURENZO, P., MAQUEDA, M. L., RUBIO, A. (Coords.) Género, violencia y derecho. Ciudad Autónoma de Buenos Aires, Editores del Puerto, 2009. pp. 221-240.

BOURDIEU, P. La dominación masculina. Barcelona, Anagrama, 2002.

BOVINO, A. "Delitos sexuales y justicia penal", en BIRGIN, H. (Comp.) Las trampas del poder punitivo. El género del Derecho Penal. Buenos Aires, Biblos, 2000. pp. 175-294.

BUTLER, J. Cuerpos que importan. Buenos Aires, Paidós, 2002.

CACHO, L. Esclavas del poder. Buenos Aires, Sudamericana, 2011.

CAVARERO, A. Horrorismo. Nombrando la violencia contemporánea. Barcelona, Anthropos, 2009.

COOK, R. y CUSACK, S. Estereotipos de Género. Perspectivas Legales Transnacionales. Bogotá, Profamilia, 2010.

FEMENÍAS, M. L. Sobre sujeto y género. (Re) Lecturas feministas desde Beauvoir a Butler. Rosario, Prohistoria, 2012. 
FEMENÍAS, M. L. "Violencia de sexo-género: el espesor de la trama”, en: LAURENZO, P; MAQUEDA, Ma. L. y RUBIO, A. (Coords.) Género, violencia y derecho. Ciudad Autónoma de Buenos Aires, Editores del Puerto, 2009. pp. 41-64.

FOUCAULT, M. La verdad y las formas jurídicas. Barcelona, Gedisa, 1991.

FOUCAULT, M. Genealogía del racismo. Buenos Aires, Altamira, 1993.

LAURENZO, P; MAQUEDA, Ma. L. y RUBIO, A. (Coords.). Género, violencia y derecho. Ciudad Autónoma de Buenos Aires, Editores del Puerto, 2009

LEGENDRE, P. El crimen del cabo Lortie. Tratado sobre el Padre. México, Siglo XXI, 1994.

LORENTE ACOSTA, M. “ ¡Me alegro de reconocerte! Juventud, identidad y violencia de género", en: Revista de Estudios de Juventud, $\mathrm{N}^{\circ}$ 86, septiembre 2009. Juventud y violencia de género, Ministerio de la Igualdad, Gobierno de España, 2009. pp. 15-30.

MACKINNON, C. Hacia una teoría feminista del Estado. Madrid, Cátedra, 1995.

MORENO, A. El arquetipo viril protagonista de la historia. Barcelona, Lasal, 1986.

OLSEN, F. “El sexo del derecho”, en: ÁVILA SANTAMARÍA, R; SALGADO, J. y VALLADARES, L. (Comps.). El género en el derecho. Ensayos críticos. Quito, Ministerio de Justicia y Derechos Humanos de Ecuador y Naciones Unidas, 2009.

OSBORNE, R. "El poder del amor (o las formas sutiles de la dominación patriarcal)", en: LAURENZO, P; MAQUEDA, M. y RUBIO, A. (coords.). Género, violencia y derecho. Buenos Aires, Editores del Puerto, 2009. pp. 143- 156.

POULANTZAS, N. Estado, poder y socialismo. México, Siglo XXI, 1986.

PLATÓN. “Teetetes”, en: PLATÓN. Obras completas, Tomo 3. Madrid, Edición de Patricio de Azcárate, 1871.

RUBIN, G. "El tráfico de mujeres: notas sobre la 'economía política' del sexo", en: Nueva Antropología, Vol. III, N³0, México, 1986. pp. 95-145.

SEGATO, R. Las estructuras elementales de la violencia. Buenos Aires, PrometeoUniversidad Nacional de Quilmes, 2003.

VARELA, N. "La nueva misoginia", en: Revista Europea de Derechos Fundamentales. $\mathrm{N}^{\circ} 19,1^{\circ}$ Semestre 2012. pp. $25-48$.

\section{Fuentes electrónicas}

LA CAPITAL. "Una nena de 12 años de Carcarañá dio a luz a una beba en el Hospital Centenario", 21 de septiembre de 2012. [en línea: 16/02/13 ] Disponible en: http://www. 
lacapital.com.ar/la-ciudad/Una-nena-de-12-aos-dio-a-luz-a-una-beba-en-el-HospitalCentenario-20120921-0042.html.

ROSARIO3.COM. "Una nena de 12 años dio a luz a una beba en el Centenario", 21 de septiembre de 2012 [en línea: 16/02/13] Disponible en: http://www.rosario3.com/ noticias/noticias. aspx?idNot=118530\&Una-nena-de-12-a\%C3\%B1os-dio-a-luz-a-unabeba-en-el-Centenario

EL TRIBUNO. "Con 9 años "muestra un cuerpo que puede ser objeto de deseo". 29 de octubre de 2012 [en línea: 13/02/13] Disponible en: http://www.eltribuno.info/ salta/217501-Con-9-anos-muestra-un-cuerpo-que-puede-ser-objeto-de-deseo.note.aspx.

EL TRIBUNO. "La culpa es de los otros". . 01 de noviembre de 2012. [ en línea: 24/12/12] Disponible en: http://www.eltribuno.info/salta/218596-La-culpa-es-de-losotros.note.aspx

INFOBAE. "Para la Justicia salteña, una nena de 9 años "puede ser objeto de deseo". 29 de octubre de 2012 [en línea: 21/12/12] Disponible en: http://www.infobae.com/ notas/678372-Para-la-Justicia-saltena-una-nena-de-9-anos-puede-ser-objeto-de-deseo. html.

PERFIL.COM. "Relativizan el abuso a una menor por tener un 'cuerpo que puede ser objeto de deseo'”. 30 de octubre de 2012 [en línea: 21/12/12] Disponible en: http://www. perfil.com/ contenidos/2012/10/29/noticia_0033.html

Fecha de recepción: 26 de marzo de 2013

Fecha de aceptación: 21 de julio de 2013 
casos. En caso de ser publicado el artículo, el/los autor/es transfieren todos los derechos de autor a Cátedra Paralela, sin cuyo permiso expreso no podrá reproducirse ninguno de los materiales allí publicados. Asimismo, Cátedra Paralela asume los derechos para editar, publicar, reproducir, distribuir copias, preparar trabajos derivados en papel y/o electrónicos e incluir el artículo en índices nacionales e internacionales o bases de datos. Se solicita a los/as colaboradores/as la entrega de la nota expresa de originalidad y cesión de los derechos de autor/a. La Revista Cátedra Paralela no se hace responsable por los trabajos no publicados ni se obliga a mantener correspondencia con los/as autores/as.

\section{Modelo Nota de Autorización - Revista Cátedra Paralela}

Por la presente autorizo a la Revista Cátedra Paralela, a la publicación del artículo de mi autoría

.........en el $\mathrm{N}^{\circ}$....... del año ......, publicación de la Escuela de Trabajo Social de la UNR y el Colegio de profesionales de Trabajo Social de la $2^{a}$ Circunscripción de la Provincia de Santa Fe.

Se deja constancia de que no corresponde retribución pecuniaria derivada del derecho de autor.

LUGAR Y FECHA:

FIRMA Y ACLARACIÓN: 